\title{
Toll-like receptor 2-deficient mice are protected from insulin resistance and beta cell dysfunction induced by a high-fat diet
}

\author{
J. A. Ehses - D. T. Meier $\cdot$ S. Wueest $\cdot$ J. Rytka $\cdot$ S. Boller $\cdot$ P. Y. Wielinga $\cdot$ \\ A. Schraenen • K. Lemaire • S. Debray • L. Van Lommel • J. A. Pospisilik • \\ O. Tschopp • S. M. Schultze $\cdot$ U. Malipiero $\cdot$ H. Esterbauer $\cdot$ H. Ellingsgaard • \\ S. Rütti • F. C. Schuit • T. A. Lutz • M. Böni-Schnetzler • D. Konrad • Marc Y. Donath
}

Received: 30 November 2009 /Accepted: 3 March 2010/Published online: 21 April 2010

(C) Springer-Verlag 2010

\begin{abstract}
Aims/hypothesis Inflammation contributes to both insulin resistance and pancreatic beta cell failure in human type 2 diabetes. Toll-like receptors (TLRs) are highly conserved pattern recognition receptors that coordinate the innate inflammatory response to numerous substances, including
\end{abstract}

J. A. Ehses and D. T. Meier contributed equally to this study.

Electronic supplementary material The online version of this article (doi:10.1007/s00125-010-1747-3) contains supplementary material, which is available to authorised users.

\section{J. A. Ehses $(\bowtie)$}

Department of Surgery, Faculty of Medicine, University of British

Columbia, Child \& Family Research Institute,

$950 \mathrm{~W} 28$ th Ave,

Vancouver, BC, CanadaV5Z 4H4

e-mail: ehses@interchange.ubc.ca

D. T. Meier $\cdot$ S. Boller $\cdot$ O. Tschopp $\cdot$ S. M. Schultze $\cdot$

H. Ellingsgaard $\cdot$ S. Rütti $\cdot$ M. Böni-Schnetzler $\cdot$ M. Y. Donath

Division of Endocrinology, Diabetes, \& Nutrition,

University Hospital of Zurich,

Zurich, Switzerland

D. T. Meier $\cdot$ S. Wueest $\cdot$ J. Rytka $\cdot$ S. Boller $\cdot$ H. Ellingsgaard $\cdot$

S. Rütti $\cdot$ M. Böni-Schnetzler $\cdot$ D. Konrad $\cdot$ M. Y. Donath

Zurich Centre for Integrative Human Physiology,

University of Zurich,

Zurich, Switzerland

S. Wueest $\cdot$ J. Rytka $\cdot$ D. Konrad

Division of Paediatric Endocrinology and Diabetology,

University Children's Hospital,

Zurich, Switzerland

\section{P. Y. Wielinga $\cdot$ T. A. Lutz}

Institute of Veterinary Physiology, and Zurich Centre for

Integrative Human Physiology,

Vetsuisse Faculty University of Zurich,

Zurich, Switzerland
NEFAs. Here we investigated a potential contribution of TLR2 to the metabolic dysregulation induced by high-fat diet (HFD) feeding in mice.

Methods Male and female littermate $T l r 2^{+/+}$and $T l r 2^{-/-}$ mice were analysed with respect to glucose tolerance, insulin sensitivity, insulin secretion and energy metabolism

A. Schraenen $\cdot$ K. Lemaire $\cdot$ S. Debray $\cdot$ L. Van Lommel

F. C. Schuit

Department of Molecular Cell Biology, Gene Expression Unit,

Katholieke Universiteit Leuven,

Leuven, Belgium

\section{J. A. Pospisilik}

Institute of Molecular Biotechnology of the Austrian Academy of Science,

Vienna, Austria

U. Malipiero

Division of Clinical Immunology, University Hospital of Zurich, Zurich, Switzerland

H. Esterbauer

Department of Medical and Chemical Laboratory Diagnostics, Medical University Vienna,

Vienna, Austria 
on chow and HFD. Adipose, liver, muscle and islet pathology and inflammation were examined using molecular approaches. Macrophages and dendritic immune cells, in addition to pancreatic islets were investigated in vitro with respect to NEFA-induced cytokine production.

Results While not showing any differences in glucose homeostasis on chow diet, both male and female Tlr $2^{-1-}$ mice were protected from the adverse effects of HFD compared with $T l r 2^{+/+}$littermate controls. Female $T l r 2^{-/-}$ mice showed pronounced improvements in glucose tolerance, insulin sensitivity, and insulin secretion following 20 weeks of HFD feeding. These effects were associated with an increased capacity of $T l r 2^{-1-}$ mice to preferentially burn fat, combined with reduced tissue inflammation. Bone-marrow-derived dendritic cells and pancreatic islets from $T l r 2^{-1-}$ mice did not increase IL-1 $\beta$ expression in response to a NEFA mixture, whereas $\mathrm{Tlr}^{+/+}$control tissues did.

Conclusion/interpretation These data suggest that TLR2 is a molecular link between increased dietary lipid intake and the regulation of glucose homeostasis, via regulation of energy substrate utilisation and tissue inflammation.

Keywords Diabetes $\cdot$ Insulin resistance $\cdot$ IL-1 .

Pancreatic islet . Toll like receptor 2

$\begin{array}{ll}\text { Abbreviations } \\ \text { BMDC } & \text { Bone-marrow-derived dendritic cell } \\ \text { BMDM } & \text { Bone-marrow-derived macrophage } \\ \text { GSIS } & \text { Glucose-stimulated insulin secretion } \\ \text { HFD } & \text { High-fat diet } \\ \text { IL-1Ra } & \text { IL-1 receptor antagonist } \\ \text { IPGTT } & \text { I.p. glucose tolerance test } \\ \text { ITT } & \text { Insulin tolerance test } \\ \text { NF-kB } & \text { Nuclear factor kB } \\ \text { TLR } & \text { Toll-like receptor }\end{array}$

\section{Introduction}

Type 2 diabetes develops as a result of a combination of both insulin resistance and pancreatic beta cell failure, resulting in hyperglycaemia. Chronic activation of the innate immune system is associated with type 2 diabetes, and evidence now suggests that both insulin resistance and beta cell failure are regulated by this inflammatory state in humans [1-3]. Indeed, clinical data have shown improved insulin resistance after treatment of type 2 diabetes patients with salicylate (via inhibition of nuclear factor $\kappa \mathrm{B}[\mathrm{NF}-\mathrm{kB}])[4,5]$, and improved beta cell insulin secretion in patients after treatment with the IL-1 receptor antagonist (IL-1Ra) [6].
Local tissue inflammation is a characteristic of the human pathology of insulin resistance in obesity and beta cell failure in type 2 diabetes $[1,2,7]$. Animal models of type 2 diabetes also show increased expression of inflammatory markers specific for cytokines, chemokines and immune cells in both insulin-responsive tissues (liver, muscle, adipose tissue) and pancreatic islets [3, 8-11]. This local tissue inflammation has now been causally linked to insulin resistance and beta cell function in a number of genetic knockout models and therapeutic intervention studies $[3,11]$. Genetic ablation studies in the high-fat diet (HFD) model have recently shown that pro-inflammatory $\mathrm{CD} 11 \mathrm{c}+$ cells are responsible for this inflammatory response in insulin sensitive tissues, impacting on insulin sensitivity [12]. However, the upstream/cell surface molecular mechanisms responsible for triggering increased tissue inflammation in obesity and type 2 diabetes are still not known.

Toll-like receptors (TLRs) are expressed in multiple tissues and are integral to mounting an immediate defence against the presence of pathogens $[13,14]$. Upon binding to their cognate ligands, TLRs recruit intracellular signalling molecules (e.g. MYD88), leading to the activation of NF$\mathrm{KB}$ and the secretion of proinflammatory cytokines and chemokines. Intriguingly, both TLR2 (which heterodimers with TLR1, or TLR6) and TLR4 recognise lipid-based structures; classically bacterial lipopeptides and lipopolysaccharide, respectively. Recent studies have shown that NEFAs, including palmitate and oleate, can activate both TLR2 and TLR4 signalling to induce proinflammatory cytokine production in various tissues, leading to an impairment of tissue-specific effects [15-19]. In addition, both $T l r 2^{-1-}$ and $T l r 4^{-1-}$ mice show improvements in the metabolic syndrome associated with HFD-induced obesity [17, 20-22]. Despite this, the mechanism underlying resistance to HFD-induced metabolic dysregulation in $\mathrm{Tlr}^{-/-}$mice is unclear.

Here we show that TLR2 signalling contributes to the adverse effects of HFD feeding in mice, impacting on insulin resistance, beta cell insulin secretion, energy substrate utilisation and tissue inflammation. These data suggest that TLR2 is a molecular link between increased dietary lipid intake and the regulation of glucose homeostasis.

\section{Methods}

Please see the Electronic supplementary material (ESM) for further detailed methods.

Materials and animals $\mathrm{Tlr}^{-/-}$mice backcrossed on $\mathrm{C} 57 \mathrm{BL} / 6 \mathrm{~J}$ for four to five generations were from the 
Jackson Laboratory (Strain B6.129-Tlr ${ }^{\text {tmlKir }} / \mathrm{J}$ ) (Bar Harbor, ME, USA) and bred in house with C57BL/6J mice to generate all $\mathrm{Tlr}^{+/+}$and $T l r 2^{-/-}$sex- and agematched littermate mice used for in vitro and in vivo studies.

Animals were housed under specific-pathogen-free conditions at the Institute of Labortierkunde, Vetsuisse faculty of the University of Zurich (Zurich, Switzerland). Experiments were performed according to Swiss veterinary law and institutional guidelines. The committee for animal welfare at the Katholieke Universiteit Leuven approved all tissue isolation protocols from mice used for Tlr2 tissue expression profiling.

Tissue expression of Tlr2 Tissue expression analysis using Affymetrix gene arrays was performed as previously described [23].

Metabolic studies Animals were fed a high-fat diet (HFD; Diet D12331) manufactured by Research Diets (New Brunswick, NJ, USA) as previously described [10, 23]. For glucose-tolerance testing, mice were injected i.p. with $2 \mathrm{mg} / \mathrm{g}$ body weight glucose (IPGTT) and insulin was measured by ELISA (Mercodia, Uppsala, Sweden). Insulintolerance testing (ITT) was performed by injecting female mice i.p. with $0.85 \mathrm{U} / \mathrm{kg}$ human insulin (Novo Nordisk, Denmark), and male mice i.p. with $1.0 \mathrm{U} / \mathrm{kg}$ insulin, as previously described [23].

Isolated adipocyte experiments Adipocyte isolation and glucose incorporation were performed as described previously [24]. Aliquots of all adipocyte fractions were used to determine mean cell diameters, as previously described [25]. At least 100 adipocytes per fraction of four independent experiments were analysed.

Indirect calorimetry and physical activity Energy expenditure and respiratory quotient (RQ) were measured for $48 \mathrm{~h}$ (two dark and light phases) by using two open-circuit calorimetry systems (Integra system, AccuScan Instruments, Columbus OH, USA). Physical activity was measured by telemetry every 5 min using Dataquest A.R.T. 3.1 software.

Cytokines and chemokines Plasma samples were assayed using mouse Luminex kits (Millipore, Billerica, MA, USA) as previously described [11].

Glucose clamp studies After $5 \mathrm{~h}$ fast, hyperinsulinaemiceuglycaemic clamps were performed in freely moving mice as previously described [24].

Total liver lipid extraction Total liver lipids were determined as recently described [24].
$R N A$ extraction and real-time PCR Total tissue RNA was prepared as described [11] from adipose tissue, liver, muscle, isolated islets, bone-marrow-derived macrophages (BMDMs), and bone-marrow-derived dendritic cells (BMDCs) according to the manufacturer's instructions (Qiagen, Hombrechtikon, Switzerland). Commercially available mouse primers (Applied Biosystems, CA, USA) were used. For ex vivo detection of islet inflammatory genes after HFD feeding, islets were initially allowed to recover for $4 \mathrm{~h}$ in suspension before extraction of total RNA.

NEFA preparation NEFAs were prepared using endotoxin-free BSA as recently described [26].

Immunohistochemistry Mouse liver and pancreatic cryosections were incubated with an anti-F4/80 primary $\mathrm{Ab}$ (clone CI:A3-1, BMA Biomedicals, Switzerland), or isotype control rat $\operatorname{IgG} 2 \mathrm{~b}$ (AbD Serotec) and counterstained with haematoxylin and eosin. F4/80 was visualised using goat anti-rat Ab (112-005-167) (Jackson ImmunoResearch, Newmarket, UK) and a donkey anti-goat Ab conjugated to HRP (Jackson 705-035-147). Images were captured on an Axioplan 2 imaging system (Zeiss, Feldbach, Switzerland) and F4/80 positive area/islet positive area was quantified using Image J software (NIH). For liver sections, three random fields of view were analysed in two sections per animal separated by $200 \mu \mathrm{m}$ (an average of 3,600 \pm 100 cells per animal). For the pancreas, all islets in four sections separated by $200 \mu \mathrm{m}$ were analysed per animal (an average of $47 \pm 7$ islets per animal).

\section{Pancreatic islet isolation and BMDM/BMDC preparation} Mouse islets were isolated by collagenase digestion, followed by Histopaque gradient centrifugation and cultured as previously described [10]. For in vitro islet experiments, islets were plated on extracellular matrix (Novamed, Jerusalem, Israel). Islets were allowed to adhere and spread on the extracellular matrix dishes for $48 \mathrm{~h}$ before initiation of experiments.

BMDMs and BMDCs were prepared as previously described [27, 28]. Briefly, bone marrow was isolated from femurs and tibias of 8- to 10-week-old female mice and cultured in macrophage medium (50\% DMEM) supplemented with $20 \%$ horse serum and 30\% L929 conditioned medium (a source of macrophage colony-stimulating factor). After 7 days cells were plated into 24 -well plates $\left(5 \times 10^{6}\right.$ cells/well) for experiments and extraction of RNA. To generate BMDCs, bone marrow prepared from femurs and tibias was cultured in non-tissue-culture-treated Petri dishes with RPMI medium supplemented with 2mercaptoethanol $(50 \mu \mathrm{M}), 10 \% \mathrm{FCS}$ and $200 \mathrm{U} / \mathrm{ml}$ granulocyte macrophage colony-stimulating factor, as pre- 
viously described [28]. After 7 days, non-adherent cells were plated into 24 -well plates $\left(5 \times 10^{6}\right.$ cells/well $)$ for experiments and extraction of RNA. The specificity of the two differentiation protocols to generate BMDMs (CD45 $+\mathrm{F} 4 / 80+\mathrm{CD} 11 \mathrm{~b}+\mathrm{Cd} 11 \mathrm{c}-)$ and BMDCs $(\mathrm{CD} 45+\mathrm{CD} 11 \mathrm{~b}$ $+\mathrm{CD} 11 \mathrm{c}+$ ) was verified by FACS analysis. BMDM and BMDC were resuspended in FACS buffer $(2 \%$ FCS, $10 \mathrm{mmol} / 1 \mathrm{EDTA}$ in PBS) and incubated with anti-mouse CD16/32 (Fc-block, BD Biosciences, Heidelberg, Germany) for $5 \mathrm{~min}$, then stained with anti-mouse CD45-biotin/SAVAPC/Cy7 (BD Biosciences), F4/80-FITC (BD Biosciences), CD11c-PE (Invitrogen) and CD11b-APC (BD Biosciences) for $20 \mathrm{~min}$. The cells were analysed with a Partec FloMax flow cytometer (Munster, Germany). 7-AAD (7-aminoactinomycin D, Invitrogen) was used to exclude nonviable cells in flow cytometric analysis. Cells were treated for $6 \mathrm{~h}$ with $\mathrm{BSA}$ or a $0.5 \mathrm{mmol} / \mathrm{l}$ palmitate:oleate $(2: 1$ molar ratio) preparation before RNA extraction.

Statistics Data are expressed as means \pm S.E. with the number of individual experiments presented in the figure legends. All data were analysed using the nonlinear regression analysis programme PRISM (GraphPad, CA, USA), and significance was tested using Student's $t$ test and analysis of variance (ANOVA) with Dunnett's or Bonferroni's post-hoc test for multiple comparison analysis. Significance was set at $p<0.05$.

\section{Results}

Tlr2 tissue expression and regulation by HFD feeding We initially profiled mouse tissue expression of Tlr2 mRNA (Fig. 1a). These data indicated that Tlr2 has a broad tissue expression profile, which includes not only organs classically described as being heavily populated by immune cells (spleen), but also insulin-sensitive tissues and the pancreatic islet. Based on this information, we analysed mRNA expression of $T l r 1,-2,-4$ and -6 in response to 20 weeks of HFD feeding in female B6 mice in perigonadal adipose tissue, skeletal quadriceps muscle, liver tissue, pancreatic islets and circulating leucocytes (Fig. 1b). Indeed, HFD feeding resulted in increased mRNA expression of some of Tlr1 $,-2,-4$ and -6 in all these tissues.

$\mathrm{Tlr}^{-1-}$ mice are resistant to the adverse effects of HFD feeding Based on published data $[15,18,19]$ and the upregulation of TLR expression by HFD, we reasoned that mice lacking Tlr2 (which are unable to signal via TLR1/2, or TLR2/6 heterodimers) might show differences in susceptibility to HFD-induced glucose intolerance. Tlr $2^{-/}$ mice were confirmed to be unresponsive to the synthetic
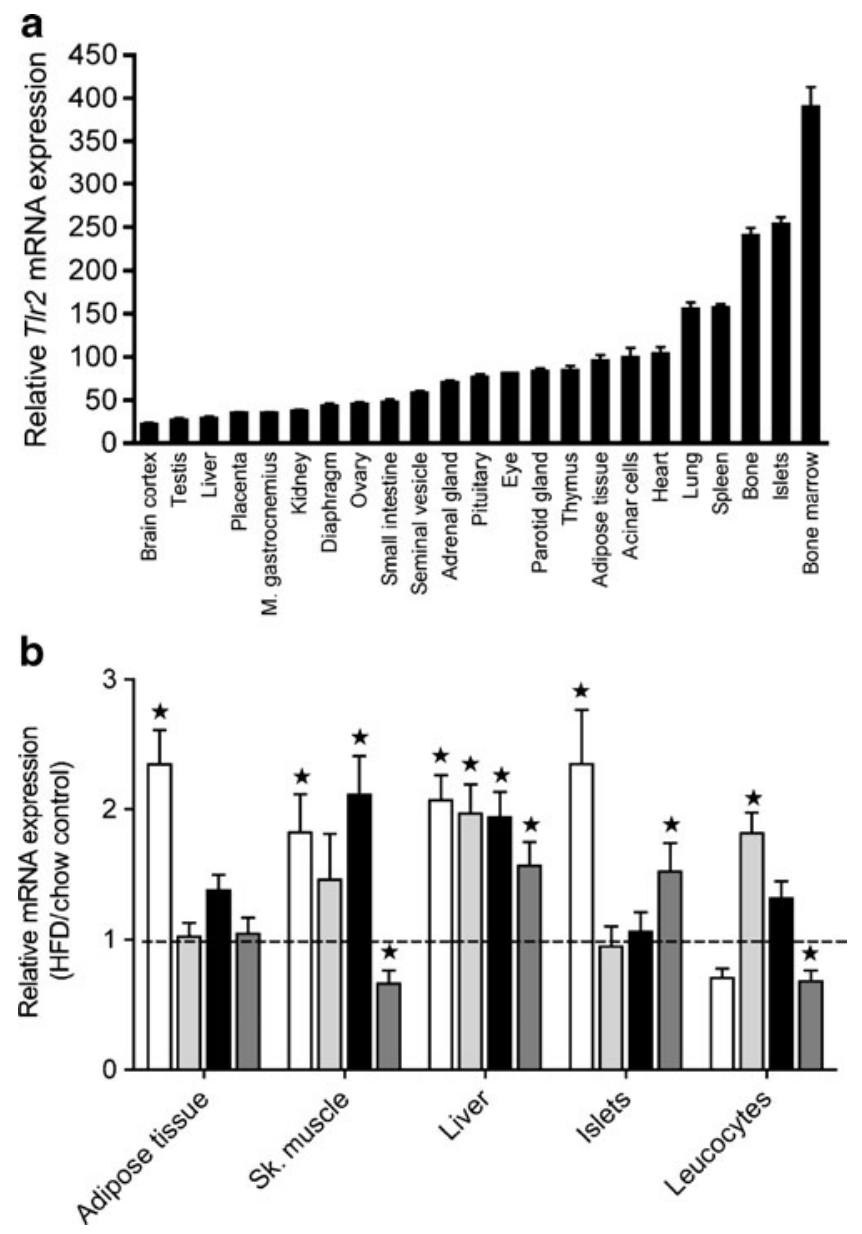

Fig. 1 HFD regulation of tissue Tlr1, -2, -4 and -6 mRNA expression. a Relative tissue expression profile of mouse Tlr 2 mRNA based on 4302.0 mouse Affymetrix gene arrays $(n=3$ for all tissues except islet, bone marrow and pituitary, where $n=4)$. b Female C57BL/6J littermate mice were fed an HFD for 20 weeks starting at 10-12 weeks of age. Perigonadal adipose tissue, quadriceps skeletal muscle, liver tissue, isolated pancreatic islets and circulating leucocytes were isolated and analysed for Tlr expression by quantitative PCR (chow $n=7$, HFD $n=8$ ). White bars, Tlr 1 ; light grey bars, Tlr2; black bars, Tlr6; dark grey bars, Tlr4. ${ }^{*} p<0.05$, as tested by Student's $t$ test compared with chow-fed age-matched control $(1.0 \pm \mathrm{SEM})$

TLR2 ligand, Pam2CSK4, in vivo (ESM Fig. 1). Further, neither female nor male $T l r 2^{-/-}$mice showed any difference in glucose tolerance or insulin sensitivity at 10 12 weeks of age when compared with littermate controls $\left(\mathrm{Tlr}^{+/+}\right)$(ESM Fig. 2a-d). Thereafter, female and male $\mathrm{Tlr}^{2^{+/+}}$and $\mathrm{Tlr} 2^{-/-}$mice were put on HFD for 20 weeks, until 32 weeks of age. HFD-induced weight gain was not different between genotypes in both female (Fig. 2a) and male mice (ESM Fig. 3a). After 12 weeks of HFD, female $T \operatorname{Tr} 2^{-/}$mice already showed improved glucose tolerance, insulin sensitivity and beta cell insulin secretion in response to a glucose challenge (ESM Fig. 4). At this age male $\mathrm{Tlr}^{-1-}$ mice were also more insulin sensitive compared with $T l r 2^{+/+}$littermates, while showing no differences in 

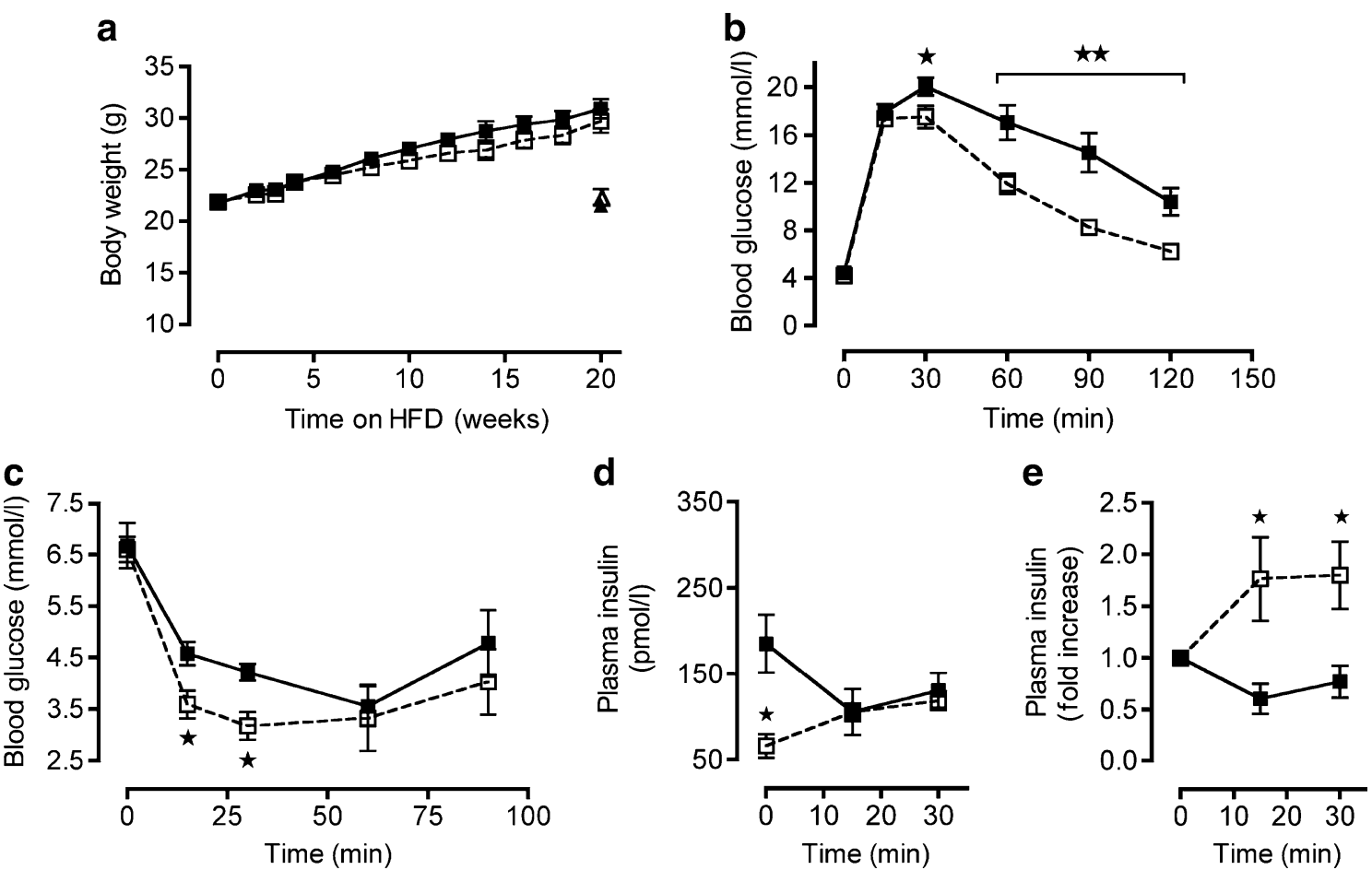

Fig. $2 T l r 2^{-/-}$mice are resistant to the adverse effects of HFD feeding. a Female $T l r 2^{+/+}$and $T l r 2^{-/-}$littermate mice were fed an HFD starting at 10-12 weeks of age, and body weight was monitored $(n=7$ for chow groups, $n=31$ for HFD Tlr $2^{+/+}$and $n=32$ for HFD $T l r 2^{-/-}$). b An IPGTT ( $2 \mathrm{~g} / \mathrm{kg}$ glucose) was performed after 20 weeks of HFD feeding (32-week-old mice; $n=21$ for HFD $T l r 2^{+/+}$and $n=22$ for HFD $\left.T l r 2^{-/-}\right)$. c An ITT (0.85 U/kg insulin) was performed after 20 weeks

glucose tolerance or insulin secretion (ESM Fig. 3b-d). After 20 weeks of HFD, female $\mathrm{Tlr}^{-1-}$ mice (aged 32 weeks) showed markedly improved glucose tolerance, insulin sensitivity and beta cell insulin secretion in response to a glucose challenge (Fig. 2b-e). Supporting improved peripheral insulin sensitivity, fasting circulating insulin levels were reduced both at 12 and 20 weeks of HFD feeding in female $T l r 2^{-/}$mice compared with $T l r 2^{+/+}$ controls (Fig. 2d and ESM Fig. 4c). Age-matched 32-weekold chow-fed female $T l r 2^{+/+}$and $T l r 2^{-/-}$mice showed no differences in glucose homeostasis (ESM Fig. 2e-f). Based on these data, we focused on female $T l r 2^{-/}$mice for the remainder of the study.

We went on to investigate insulin target tissue inflammation and insulin sensitivity in addition to examining islet inflammation and islet insulin secretion. HFD-fed female $T l r 2^{-/}$mice had reduced perigonadal fat pad weight compared with wild-type animals, in addition to having smaller adipocytes that displayed improved insulinstimulated glucose uptake (Fig. 3a-d). This was consistent with increased GLUT4 protein levels in whole adipose tissue of $\mathrm{Tlr}^{-/-}$mice (ESM Fig. 5). Interestingly, HFDinduced adipose tissue cytokine mRNA expression was similar between genotypes, with only the chemokine, of HFD feeding (32-week-old mice; $n=8$ for HFD Tlr $2^{+/+}$and $n=7$ for HFD $T l r 2^{-/-}$). d, e Insulin secretion during an IPGTT performed after 20 weeks of HFD feeding (32-week-old mice; $n=8$ for HFD Tlr $2^{+/+}$ and $n=7$ for HFD $T l r 2^{-/-}$). Black triangles, chow $T l r 2^{+/+}$; white triangles, chow $T l r 2^{-/}$; black squares and unbroken line, HFD $T l r 2^{+/+}$; white squares and broken line, HFD Tlr $2^{-/-}{ }^{*} p<0.05$ and ${ }^{*} * p<0.01$, as tested by Student's $t$ test compared with $T l r 2^{+/+}$control

Mcp-1, and the macrophage marker, Cd68, showing reductions in mRNA in Tlr $2^{-1-}$ mice on HFD (Fig. 3e-g). Further, mRNA expression of $C d 36$, the fatty acid translocase known to associate with TLR2 [29], was unchanged in adipose tissue (Fig. 3h).

In agreement with reduced adiposity, circulating leptin, MCP-1 and TNF- $\alpha$ levels were significantly reduced in female $\mathrm{Tlr}^{-/}$animals after 20 weeks of HFD feeding (ESM Table 1). However, we did not detect differences in circulating resistin, IL-6, cholesterol, NEFAs or ketones. In support of improved insulin sensitivity, circulating triacylglycerol levels were significantly reduced in $\mathrm{Tlr}^{-/-}$mice on HFD (ESM Table 1).

Given the reduced adiposity of female $T l r 2^{-/-}$mice on HFD, we investigated energy homeostasis in these animals during HFD feeding. Despite reduced adiposity, Tlr $2^{-/-}$ mice tended to consume more calories (10\% more) (Fig. 4a). At the same time, we observed a parallel $10 \%$ increase in total energy expenditure, an effect that was more pronounced during dark phases (Fig. $4 \mathrm{~b}, \mathrm{c}$ ). Increased total energy expenditure was not due to increased physical activity (Fig. 4d,e). Interestingly, Tlr $2^{-/-}$mice preferentially used lipids as an energy source as indicated by a significantly reduced RQ, especially during the light phases 
a

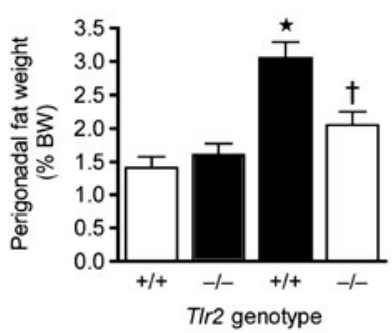

e

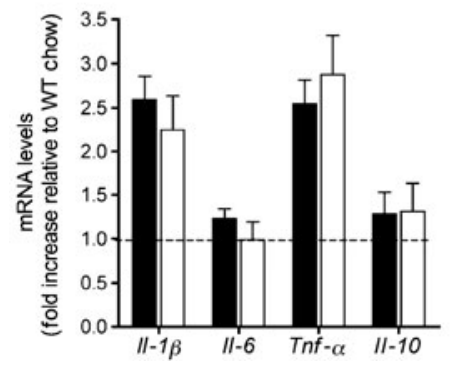

b

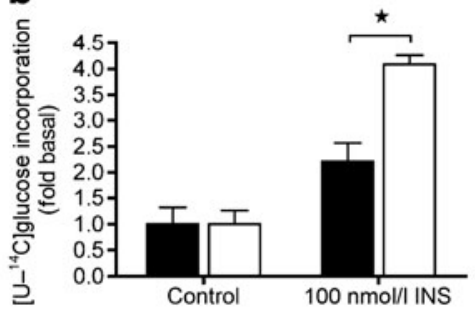

C

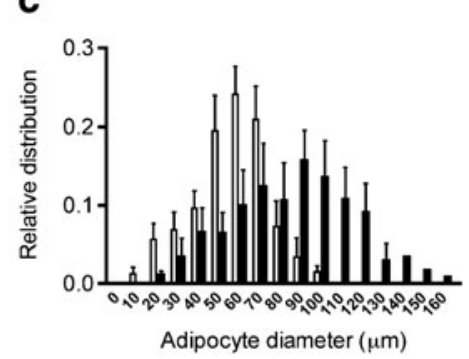

d

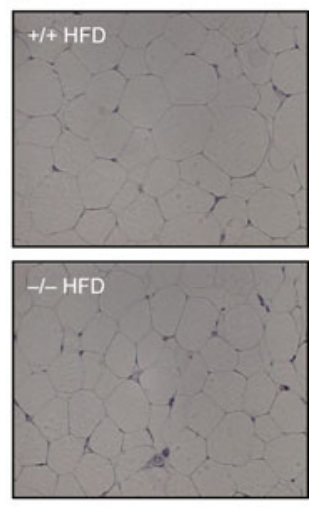

f

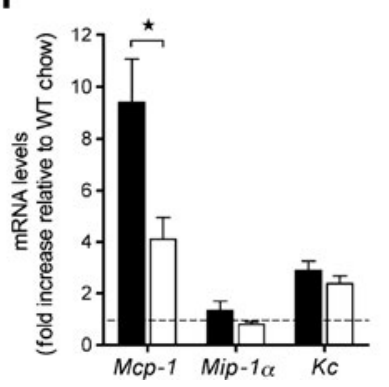

g

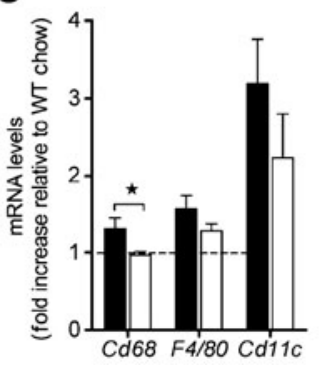

h

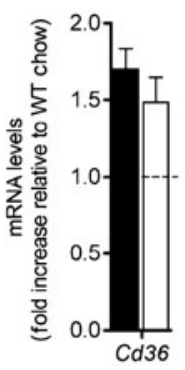

Fig. 3 Adipose tissue in female $\mathrm{Tlr}^{+/+}$and $\mathrm{Tlr} 2^{-/-}$mice after 20 weeks of HFD feeding. a Perigonadal fat pad weight as \% body weight in chow- and HFD-fed female $T l r 2^{+/+}$and $T l r 2^{-/-}$mice $(n=13$ chow $T l r 2^{+/+}, n=15$ chow $T l r 2^{-/-}, n=21$ HFD $T l r 2^{+/+}, n=23$ HFD $\left.T l r 2^{-/-}\right) .{ }^{*} p<0.05$ relative to $T l r 2^{+/+}$chow control and $\dagger p<0.05$ relative to $T l r 2^{+/+}$HFD, as tested by ANOVA with Newman-Keuls post hoc test. b Insulin (INS)-stimulated glucose incorporation in isolated perigonadal adipocytes ( $n=4$ per group). $* p<0.05$, as tested by

(Fig. 4f,g). This was consistent with increased skeletal muscle Acoxl and Mcad mRNA expression (enzymes involved in beta-oxidation) in $T l r 2^{-/}$mice, while other genes involved in fatty acid uptake $(\mathrm{Cd} 36)$ and inflammation were unchanged (Fig. $4 \mathrm{~h}-\mathrm{k}$ ). However, at this time point we did not detect differences in skeletal muscle triacylglycerols or glycogen content between genotypes (ESM Fig. 6). In summary, female $\mathrm{Tlr}^{-/-}$mice show reduced adiposity on HFD compared with $\mathrm{Tlr}^{+/+}$littermates. This was consistent with a reduced RQ, and increased mRNA expression of some genes involved in beta-oxidation in skeletal muscle. Overall energy intake and expenditure were balanced, possibly explaining why body weight did not differ between groups. Finally, adipose tissue and skeletal muscle inflammation due to HFD feeding was not strongly impacted by lack of TLR2 signalling.

$\mathrm{Tlr} 2^{-/}$mice are protected from liver insulin resistance, hepatosteatosis and liver inflammation on HFD We performed hyperinsulinaemic-euglycaemic clamps to assess peripheral insulin sensitivity in female $T l r 2^{-/-}$and $T l r 2^{+/+}$ mice after HFD feeding for 20 weeks. In agreement with enhanced whole body insulin sensitivity observed during
Student's $t$ test. c Perigonadal adipocyte size distribution $(n=4$ per group). $\mathbf{d}$ Representative image of perigonadal adipose tissue. $\mathbf{e}, \mathbf{f}, \mathbf{g}$ Relative cytokine, chemokine and macrophage/dendritic cell marker mRNA expression in perigonadal adipose tissue compared with chowfed $T l r 2^{+/+}$animals ( $n=8$ for HFD Tlr $2^{+/+}$and $n=7$ for HFD $T l r 2^{-/-}$). h Cd36 mRNA expression compared with chow-fed Tlr2 ${ }^{+/+}$animals ( $n=8$ for HFD Tlr $2^{+/+}$and $n=7$ for HFD Tlr $2^{-/-}$). Black bars, Tlr $2^{+/+}$; white bars, $T l r 2^{-1}$. ${ }^{*} p<0.05$ as tested by Student's $t$ test

the ITT (Fig. 2c), glucose infusion rates were increased in $\mathrm{Tlr}^{-/-}$mice concomitant with insulin-stimulated glucose turnover (Fig. 5a-c and ESM Fig. 7). Further, liver insulin sensitivity was preserved in Tlr $2^{-/}$mice, as demonstrated by a significant reduction in hepatic glucose production during the hyperinsulinaemic clamp (Fig. 5d). Lipid content was reduced in livers of $\mathrm{Tlr}^{-/}$mice, suggesting protection against the development of hepatosteatosis under HFD (Fig. 5f). Consistent with this, mRNA of the fatty acid translocase, $C d 36$, was strongly reduced in $T l r 2^{-/}$mice, whereas genes involved in beta-oxidation (Acoxl, $C p t 1 a)$, oxidative metabolism (Pgcl $\alpha$ [also known as Ppargcla]) or lipogenesis (Fas) were unchanged relative to controls (Fig. $5 \mathrm{~g}$ ). Indeed, $\mathrm{Tlr}^{-/-}$mice were protected from HFD-induced liver $I l-1 \beta$ (also known as $I l 1 b$ ), $M C P$ 1 and $C d 68$ mRNA expression compared with $T l r 2^{+/+}$ controls (Fig. 5h-j). However, other HFD-induced cytokines (IL-6 [also known as Il6], Tnf- $\alpha$ [also known as $T n f$ ], $I L-10$ [also known as $I l 10]$ ) and chemokines (MIP$1 \alpha$ [also known as $\mathrm{Clcl3}$ ], $\mathrm{Kc}$ [also known as $\mathrm{Cxcl1}$ ]) were unchanged between genotypes (Fig. $5 \mathrm{~h}-\mathrm{j}$ ). Consistent with mRNA data, numbers of liver F4/80+ cells (a macrophage marker) were unchanged between genotypes on HFD $\left(13.7 \pm 1.1 \%\right.$ in $\operatorname{Tlr}^{+/+}[n=8]$ vs $13.5 \pm 1.3 \% \mathrm{~F} 4 /$ 
a

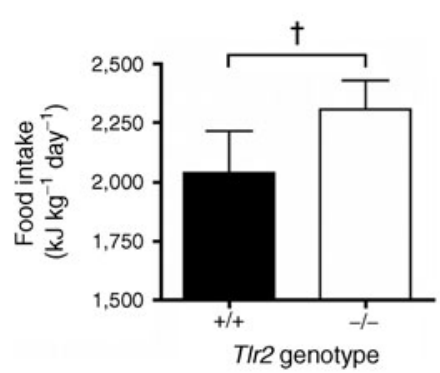

d

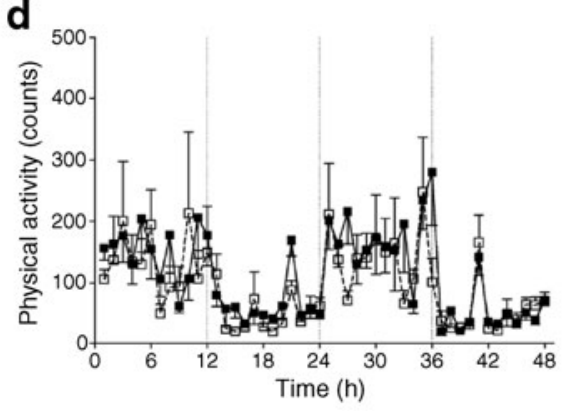

f

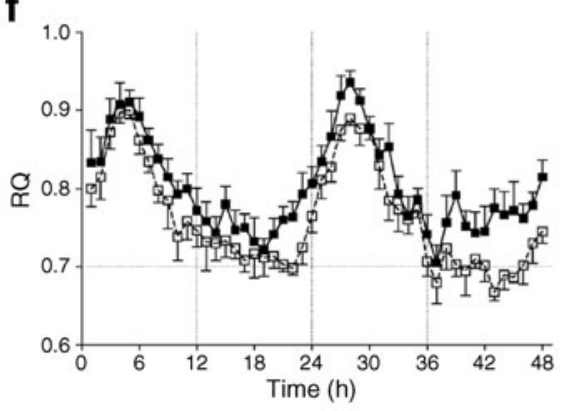

\section{b}

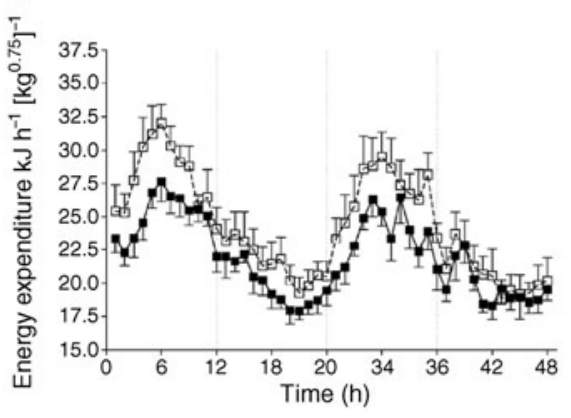

C

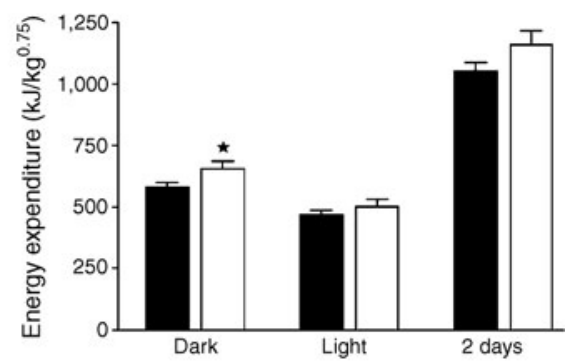

e

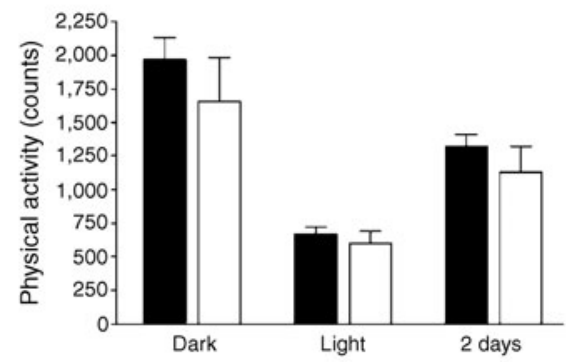

g
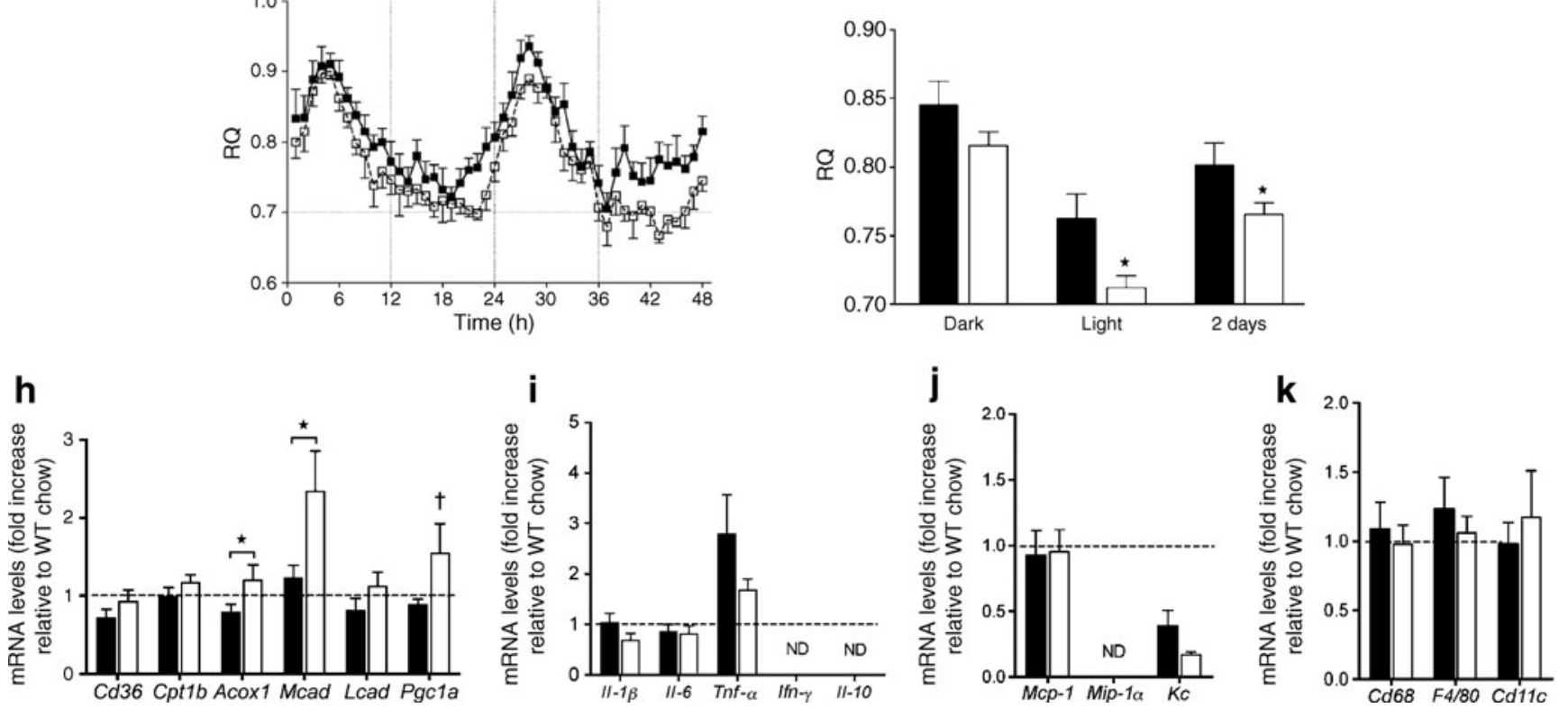

Fig. 4 Indirect calorimetry and muscle in female $T l r 2^{+/+}$and $T l r 2^{-/-}$ mice after 20 weeks of HFD feeding. a Food intake monitored over four consecutive days as normalised to body weight $\left({ }^{\dagger} p=0.24\right)$. Energy expenditure calculated continuously over $48 \mathrm{~h}$ (b) and total summed energy expenditure during dark and light phases (c). Time: $0 \mathrm{~h}=18: 00 \mathrm{~h}$, and represents lights off; $12 \mathrm{~h}$ dark and light phases are separated by vertical lines. Physical activity monitored by telemetry continuously over $48 \mathrm{~h}$ (d) and averaged during dark and light phases (e). Respiratory quotient (RQ) calculated continuously over 48 h (f) and averaged during dark and light phases (g). $n=6$ per group for all

$80+$ cells/total cells in $\left.\operatorname{Tlr}^{-/-}[n=7]\right)$. Thus, female $\mathrm{Tlr}^{-/-}$mice are protected from liver insulin resistance, hepatosteatosis and some markers of inflammation on HFD.

measurements. ${ }^{*} p<0.05$ between genotypes as tested by Student's $t$ test. h Relative mRNA expression of genes involved in fatty acid metabolism in quadriceps muscle in female $T l r 2^{+/+}$and $T l r 2^{-/-}$mice after 20 weeks of HFD feeding ( $n=8$ for HFD $T l r 2^{+/+}$and $n=7$ for HFD Tlr $2^{-/}$). ${ }^{*} p<0.05$ between genotypes as tested by Student's $t$ test, ${ }^{\dagger} p=0.067$. Relative cytokine (i), chemokine (j) and macrophage/ dendritic (k) cell marker mRNA expression $\left(n=8\right.$ for HFD Tlr $2^{+/+}$and $n=7$ for HFD $T l r 2^{-1-}$ ). Black bars, or black squares with unbroken line, $T l r 2^{+/+}$; white bars, or white squares with broken line, $T l r 2^{-1-}$. $\mathrm{BW}$, body weight; ND, not detectable

$\mathrm{Tlr}^{-/}$mice are protected from impaired beta cell insulin secretion and islet inflammation on HFD We isolated pancreatic islets after 20 weeks of HFD feeding from female littermate $T l r 2^{+/+}$and $T l r 2^{-/}$mice. Islets from $T l r 2^{-/}$mice 


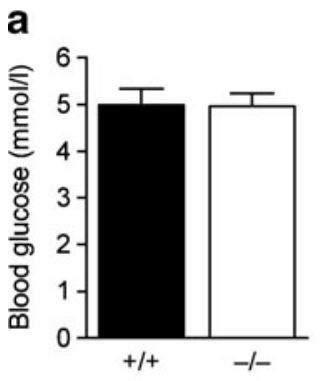

e
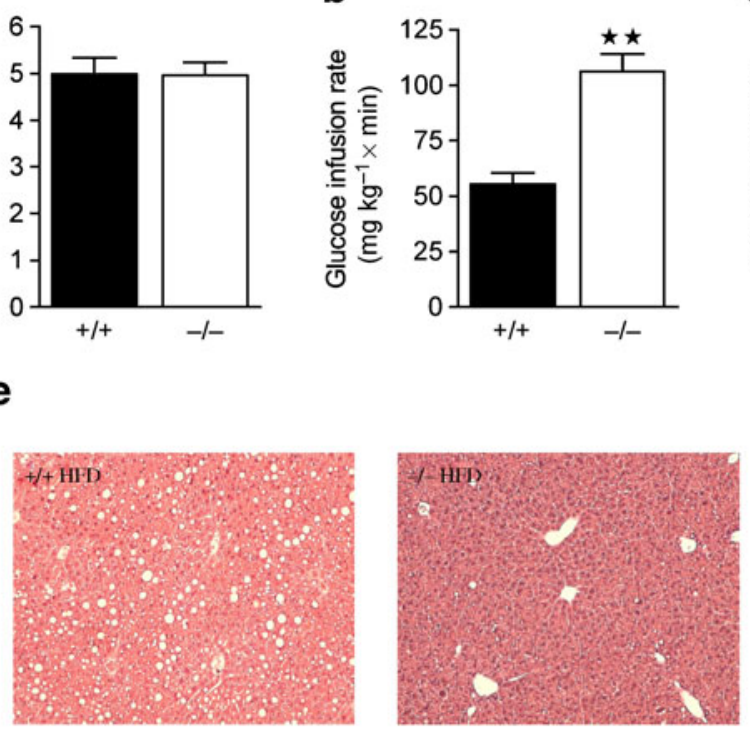

b
C

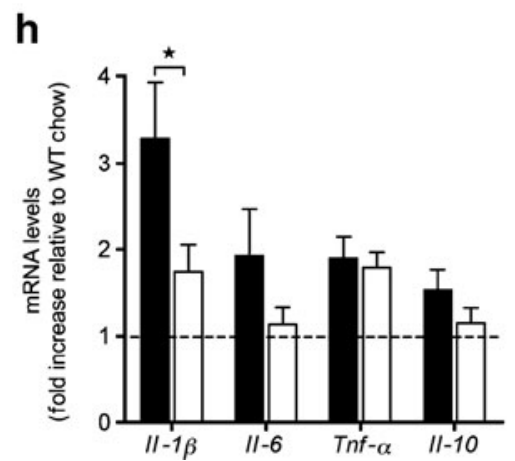

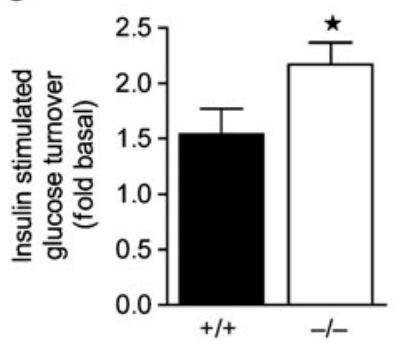

f

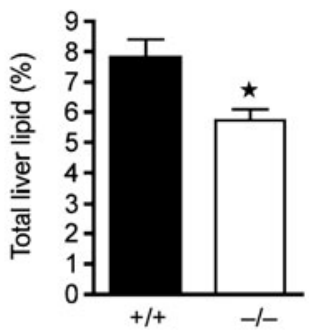

d

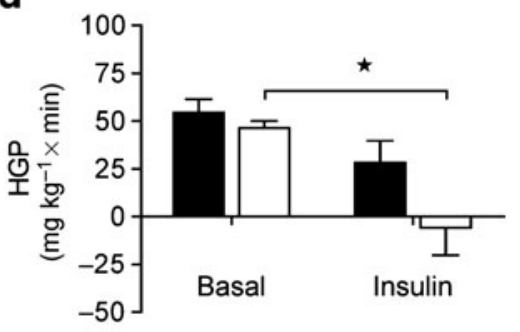

g

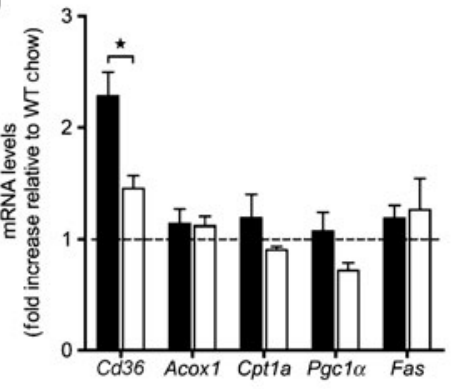

j

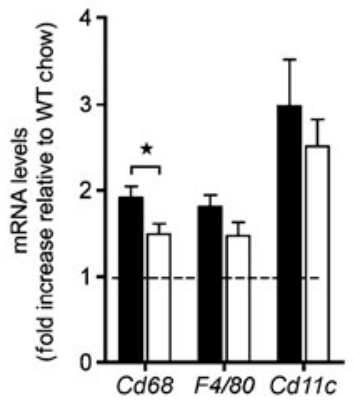

Fig. 5 Liver in female $T l r 2^{+/+}$and $T l r 2^{-/-}$mice after 20 weeks of HFD feeding. Hyperinsulinaemic-euglycaemic clamps were performed after 20 weeks of HFD feeding in female $T l r 2^{+/+}$and $T l r 2^{-/-}$ littermates. Blood glucose during clamping (a) and glucose infusion rate $(\mathbf{b})(n=4)$. c Insulin-stimulated glucose turnover in female $T l r 2^{+/+}$ and $T l r 2^{-/}$littermates $(n=4)$. d Suppression of hepatic glucose production (HGP) during clamp $(n=4)$. Representative liver stained with haematoxylin and eosin (e) and total liver lipids (f) $(n=7$ for HFD $T l r 2^{+/+}$and $n=8$ for HFD $T l r 2^{-/-}$). g Relative mRNA expression of genes involved in fatty acid transport $(C d 36)$, beta-oxidation (Acoxl, Cptla, Pgcl $\alpha$ ) and lipogenesis (Fas). Relative cytokine (f), chemokine (i) and macrophage/dendritic (j) cell marker mRNA expression in liver isolated from female HFD $T l r 2^{+/+}$and $T l r 2^{-/}$ littermates compared with chow $T l r 2^{+/+}$controls $\left(n=8\right.$ for HFD $T l r 2^{+/+}$ and $n=7$ for HFD $T l r 2^{-/-}$). Black bars, $T l r 2^{+/+}$; white bars, $T l r 2^{-1-}$. ${ }^{*} p<0.05$ and $* * p<0.01$ as tested by Student's $t$ test compared with Tlr $2^{+/+}$control

as Itgax) (Fig. 6b) (for $C d 68 r^{2}=0.91, p=0.0003$; for $F 4 / 80$ $r^{2}=0.92, p=0.0006$; for $\left.C d 11 c r^{2}=0.60, p=0.02 ; n=8\right)$. By contrast, islets from $\mathrm{Tlr}^{-/-}$mice on HFD were protected from increased $I l-1 \beta, C d 68$ and $F 4 / 80$ mRNA (Fig. 6c-e). Furthermore, Il-6, Tnf- $\alpha, M c p-1$ and $K c$ mRNA was also significantly reduced in $T \operatorname{Tr} 2^{-/}$vs $T \operatorname{lr} 2^{+/+}$islets on HFD, with no effect on islet $C d 36$ expression (Fig. 6c-f). No reductions in these inflammatory markers were observed in islets isolated from sex- and age-matched chow-fed Tlr $2^{-/-}$ compared with $T l r 2^{+/+}$mice (not shown). In contrast to F4/ 80 mRNA data, and similar to the liver, the amount of islet F4/80+ cells were unchanged in HFD $\mathrm{Tlr}^{-1-}$ mice (percentage area of $\mathrm{F} 4 / 80+$ cells of total islet area: $1.9 \pm$ $0.4 \%$ in $T l r 2^{+/+}[n=4]$ vs $1.8 \pm 0.4 \%$ in $\left.T l r 2^{-/} \quad[n=4]\right)$, 
a

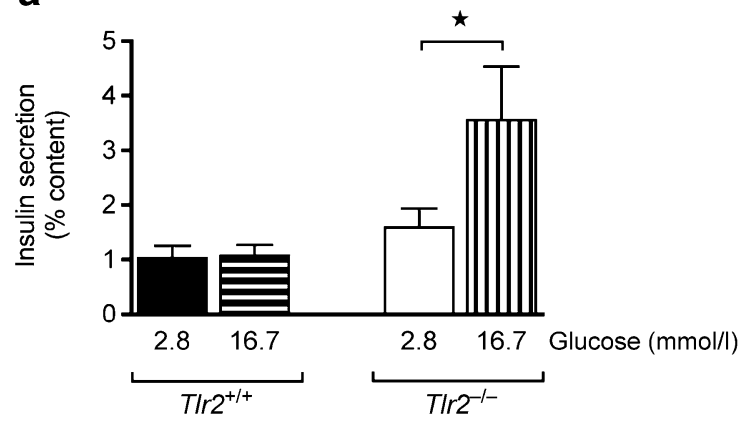

C

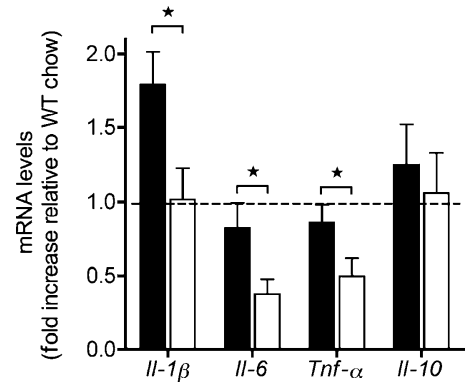

d

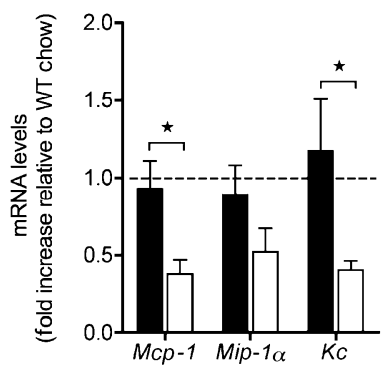

b

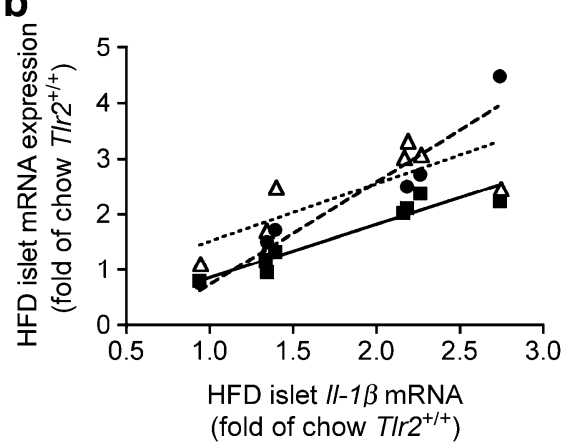

e

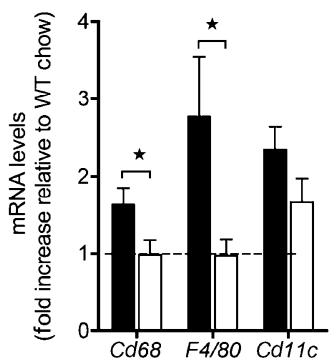

f
Fig. 6 Pancreatic islet in female $T l r 2^{+/+}$and $T l r 2^{-/-}$mice after 20 weeks of HFD feeding. a Pancreatic islets were isolated after 20 weeks of HFD feeding in $T l r 2^{+/+}$and $T l r 2^{-/-}$littermates and static glucose-stimulated insulin secretion was performed using $2.8 \mathrm{mmol} /$ 1 glucose and $16.7 \mathrm{mmol} / \mathrm{l}$ glucose $(1 \mathrm{~h}$ each, 15 islets/well) and normalised for total islet insulin content. Content was unchanged between genotypes ( $n=8$ for HFD $T l r 2^{+/+}$and $n=7$ for HFD $T l r 2^{-/-}$). ${ }^{*} p<0.05$ as tested by Student's $t$ test. b Pancreatic islets isolated from chow- and HFD-fed $\mathrm{Tlr}_{2}{ }^{+/+}$mice were analysed for $\mathrm{Il}-1 \beta, \mathrm{Cd} 68, \mathrm{~F} 4 /$ 80 and $C d 11 c$ mRNA expression by quantitative PCR. There is a strong positive correlation between islet $I l-1 \beta$ mRNA and islet $C d 68$,

possibly suggesting an altered activation status of liver and islet macrophages/dendritic cells in $\mathrm{Tlr}^{-/-}$vs $\mathrm{Tlr}^{+/+}$mice on HFD.

Finally, analysis of total peripheral leucocytes did not show differences in cytokine mRNA $(I l-1 \beta, \operatorname{Tnf}-\alpha)$ or macrophage marker expression (Cd68, F4/80) between $T l r 2$ genotypes on HFD (data not shown), supporting the tissue specificity of the inflammatory response.

Impaired inflammatory response of BMDCs and islets to NEFAs in Tlr2 $2^{--}$mice Numbers of F4/80+ cells in the liver and islets were unchanged, despite reductions in $I l-1 \beta$ mRNA in these tissues in $T l r 2^{-/}$mice. Thus, we hypothesised that tissue immune cells (macrophages and/ or dendritic cells) from $\mathrm{Tlr}^{-/-}$mice and/or parenchymal tissue itself may display a reduced ability to mount an inflammatory response to certain ligands present during HFD feeding. BMDMs and BMDCs from $\mathrm{Tlr}^{+/+}$and $\mathrm{Tlr} 2^{-/-}$mice were cultured for $6 \mathrm{~h}$ in the presence of endotoxin-free BSA control or a mix of $0.5 \mathrm{mM}$ palmitate: oleate $(2: 1)$. Indeed, BMDCs from $T l r 2^{-/}$mice displayed an attenuated $I l-1 \beta$ mRNA response to the NEFAs, whereas
F4/80 or $C d 11 c$ mRNA under HFD conditions (for $C d 68 r^{2}=0.91, p=$ 0.0003 , black squares; for $F 4 / 80 r^{2}=0.92, p=0.0006$, black circles; for Cd11 c $r^{2}=0.60, p=0.02$, white triangles; $\left.n=8\right)$. Relative cytokine (c), chemokine (d) and macrophage (e) marker mRNA expression in pancreatic islets isolated from female HFD-fed $T l r 2^{+/+}$and $T l r 2^{-/-}$ littermates compared with chow $T l r 2^{+/+}$controls $\left(n=8\right.$ for HFD $T l r 2^{+/+}$ and $n=7$ for HFD $T l r 2^{-/}$). f Relative islet $C d 36$ mRNA expression in HFD-fed $T l r 2^{+/+}$and $T l r 2^{-/-}$mice $\left(n=8\right.$ for HFD $T l r 2^{+/+}$and $n=7$ for HFD Tlr $2^{-/-}$). Black bars, Tlr $2^{+/+}$; white bars, Tlr $r 2^{-/-}$. ${ }^{*} p<0.05$ as tested by Student's $t$ test compared with $T l r 2^{+/+}$control

BMDMs did not (Fig. 7a,b). Both BMDMs and BMDCs from $\mathrm{Tlr}^{-/-}$mice were unable to respond to the $\operatorname{Tl} 2$ ligand Pam2CSK4 (ESM Fig. 8). As a representative tissue, we also investigated the response of pancreatic islets from $T l r 2^{+/+}$and $T l r 2^{-/}$mice to NEFAs. Palmitate $(0.1 \mathrm{mmol} / \mathrm{l})$ induced $I l-1 \beta$ mRNA 2.5 -fold in $T l r 2^{+/+}$islets, whereas this effect was absent in islets from mice lacking $T l r 2\left(T l r 2^{-/}\right)$ (Fig. 7c). This effect was specific for the NEFA palmitate, as oleate (18:1) alone was unable to increase islet $I l-1 \beta$ mRNA expression (not shown). The IL-1 $\beta$-induced $I l-1 \beta$ auto-amplification system [30] was unchanged in $T l r 2^{-/}$ islets vs $\mathrm{Tlr}^{+/+}$controls, indicating no developmental defect in $\mathrm{Tlr}^{-/-}$islets with respect to the induction of Il-1 $\beta$ mRNA expression (Fig. 7d).

\section{Discussion}

The impact of inflammation on insulin resistance and beta cell dysfunction has been confirmed clinically in patients with type 2 diabetes [3,6]. Nevertheless, the triggering mechanism responsible for induction of the 
Fig. 7 Impaired inflammatory response to NEFAs in BMDCs and islets of $T l r 2^{-/-}$mice.

BMDMs (a) and BMDCs (b) were prepared from $\mathrm{Tlr}^{+/+}$and $T l r 2^{-1-}$ mice as described and treated for $6 \mathrm{~h}$ with BSA control or palmitate:oleate $(16: 0: 18: 1$, $2: 1$ molar ratio, $0.5 \mathrm{mmol} / \mathrm{l})$. RNA was extracted and $I L-1 \beta$ mRNA is shown relative to $18 \mathrm{~S}$ $\left(n=3\right.$ for $T l r 2^{+/+}, n=4$ for

$T l r 2^{-/-}$). c Regulation of islet

$I L-1 \beta$ mRNA by $48 \mathrm{~h}$ treatment with $0.1 \mathrm{mmol} / 1$ palmitate in $T l r 2^{+/+}$and $T l r 2^{-/-}$islets $(n=3-7)$. d Regulation of islet $I L-1 \beta$ mRNA by $48 \mathrm{~h}$ treatment with $0.2 \mathrm{ng} / \mathrm{ml} \mathrm{IL-} 1 \beta$ in $T l r 2^{+/+}$ and $T l r 2^{-/-}$islets $(n=3-7)$. Black bars, Tlr $2^{+/+}$; white bars, $T l r 2^{-/-} \cdot{ }^{*} p<0.05$ as tested by Student's $t$ test compared with BSA genotype control a

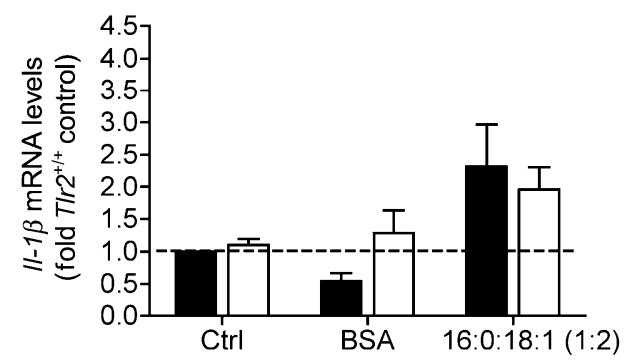

C

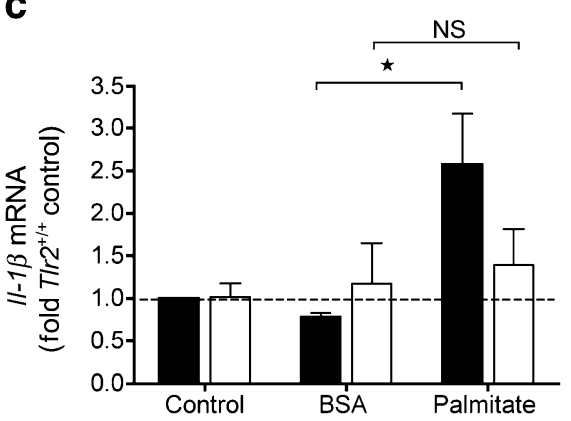

b

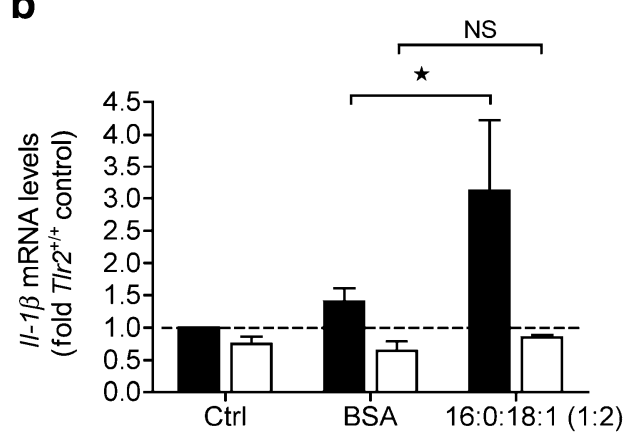

d

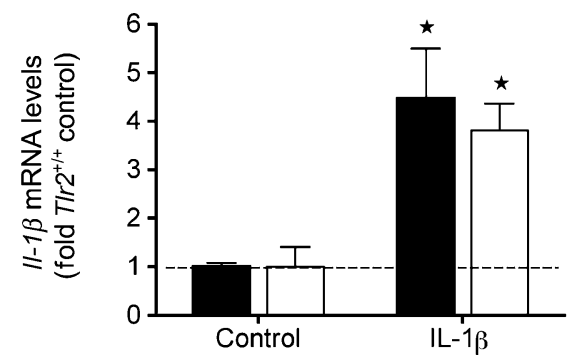

inflammatory response in obesity and type 2 diabetes is not known. Recent studies have implicated TLR4 and its associated co-receptor, CD14, in HFD- and NEFAstimulated tissue inflammation and insulin resistance [17, 21, 22, 31]. Here, we show that TLR2 signalling is also detrimental for proper glucose homeostasis under HFD conditions. Overall, TLR2 deficiency protected from HFD-induced insulin resistance and beta cell dysfunction via regulation of energy substrate utilisation and tissue inflammation.

During the preparation of this manuscript, another study on the role of genetic deletion of TLR2 during HFD feeding was published [20]. Overall, their data on improved whole body glucose homeostasis and liver lipid content are consistent with our data. Our data extends on these data, however, indicating that lack of TLR2 positively regulates energy-substrate utilisation, hepatic and adipose tissue insulin sensitivity, beta cell insulin secretion and liver and islet tissue inflammation. Furthermore, our in vitro data suggest a role for TLR2 in tissue immune cells (BMDCs) or parenchymal tissue itself (islets) in regulating the inflammatory response to elevated fatty acids during HFD feeding.

Our male and female $T l r 2^{-/}$mice were more prone to obesity on HFD than the male Tlr $2^{-/}$mice used in the study of Himes and Smith [20]. This may be explained by differences in diets used, or the use of littermate controls in our study, which was not explicitly stated in the other study. Indeed, we also performed our experiments on nonlittermate-controlled $T l r 2^{+/+}$and $T l r 2^{-/-}$mice initially, with data matching those of Himes and Smith in male mice (not shown). Repeating the study on littermate mice resulted in the sexually dimorphic phenotype shown here in response to HFD, and a milder resistance to obesity phenotype than published [20]. Interestingly, our data are similar to a published report on $T l r 4^{-/-}$mice [17], which also showed sexual dimorphism in their resistance to the adverse effects of HFD feeding, with males showing only a partial resistance compared with females. We cannot explain these differences, but it will be interesting to investigate the effects of sex on tissue inflammation with respect to obesity and diabetes.

A reduced $R Q$, together with a reduction in adiposity and liver lipid content in $T l r 2^{-/-}$animals, suggests that fatty acids are being shunted away from the liver to be increasingly oxidised in other tissues (such as skeletal muscle) in HFD Tlr $2^{-/-}$mice. This would be consistent with a diminished capacity of the liver to take up lipids due to suppressed Cd36 mRNA expression. TLR2 has been shown to associate with CD36 at the plasma membrane following receptor ligand activation, suggesting that the absence of TLR2 activation in the liver may protect from fatty acid uptake [29].

Reduced adiposity and reduced hepatosteatosis were also consistent with overall improvements in whole body and hepatic insulin sensitivity as determined by the hyperinsulinaemic-euglycaemic clamp. Thus, our data show for the first time that TLR2 regulates hepatic insulin sensitivity during HFD, extending findings that reduced TLR2 expression by antisense oligonucleotides improved insulin signalling in muscle and white adipose tissue of HFD-fed mice [32]. 
Beyond improved insulin sensitivity, we also observed improvements in beta cell insulin secretion in response to glucose load, both in vivo and in vitro. Thus, the overall improved glucose tolerance of HFD $\mathrm{Tlr}^{-/-}$mice was due to improved insulin sensitivity and beta cell insulin secretion, which correlated well with a partially attenuated tissue inflammatory response in the liver and islet.

We went on to investigate why tissue inflammation might be suppressed in Tlr2 $2^{-/}$mice on HFD. Reductions in tissue inflammation may be due to reduced immune cell content of tissues, a reduced activation status of tissue immune cells or reduced inflammation of the parenchymal tissue. Despite reductions in $C d 68$, and/or F4/80 mRNA in adipose tissue, liver and in islets, we did not observe differences between genotypes in the number of $\mathrm{F} 4 / 80+$ cells by immunohistochemistry in the liver or islet. Thus, we hypothesised that the activation status of proinflammatory immune cells in $T l r 2^{-/-}$mice or the parenchymal tissue itself had a reduced capacity to mount an inflammatory response under HFD conditions. Pro-inflammatory $\mathrm{CD} 11 \mathrm{c}+$ cells have been causally linked to tissue inflammation and the induction of insulin resistance in response to HFD in the B6 mouse [12]. Our data showing increased Cd11c mRNA expression during HFD feeding in adipose tissue, liver tissue and islets are consistent with the notion that $\mathrm{CD} 11 \mathrm{c}+$ cells are recruited to these tissues during obesity $[19,33]$. Indeed, Tlr $2^{-/}$BMDCs (CD45+CD11b $+\mathrm{Cd} 11 \mathrm{c}+)$ showed a refractory response to NEFA-induced Il- $1 \beta$ mRNA in vitro, whereas BMDMs (CD45+F4/80 $+\mathrm{CD} 11 \mathrm{~b}+\mathrm{Cd} 11 \mathrm{c}-)$ did not. The pancreatic islet was also tested as a representative tissue with respect to NEFA induction of $I l-1 \beta$ mRNA. Consistent with the effects seen in BMDCs and our in vivo effects, $T l r 2^{-/-}$islets were also refractory to palmitate-induced $I L-1 \beta$ mRNA. We previously found no effect of oleate on mouse islet $I l-1 \beta$ mRNA (not shown) [26]. These data suggest that $\mathrm{Tlr}^{-/} \mathrm{CD} 11 \mathrm{c}+$ cells are resistant to the effects of NEFAs present in HFD, possibly resulting in the reduced tissue inflammation seen in the liver and islets of HFD $T l r 2^{-/-}$mice. However, given the broad tissue expression of Tlr2 mRNA, we cannot conclude whether the observed reductions in tissue inflammation in vivo are due to an immune cell, or parenchymal cell, origin.

Recent data also suggest a role for TLR2 in human type 2 diabetes. One study has shown increased production of TLR2 protein on circulating monocytes following feeding of a high-fat high-carbohydrate meal in healthy lean human participants [34]. Evidence for increased TLR2 protein levels on monocytes and increased circulating TLR2 ligands in recently diagnosed type 2 diabetes patients has also been reported [35]. Monocytes from these type 2 diabetes individuals showed increased proinflammatory cytokine secretion following TLR2 stimulation [35]. Fur- ther, adipose tissue from participants with obesity and type 2 diabetes compared with controls also showed increased protein levels of TLR2 [36]. Whether TLR2 activation also contributes to insulin resistance and beta cell dysfunction in humans with type 2 diabetes awaits further investigation.

In summary, these data show that deficiency in TLR2mediated signalling has a positive impact on glucose homeostasis, insulin sensitivity, insulin secretion and energy-substrate utilisation during HFD feeding. The overall improved metabolic phenotype of $T l r 2^{-/}$mice on HFD is likely to be due to both reduced fat accumulation and reduced tissue inflammation, impacting on tissuespecific functions to improve both insulin sensitivity and secretion.

Acknowledgements We thank R.M. Zinkernagel and A.A. Navarini (University Hospital of Zurich) for the $T l r 2^{--}$mice. We thank M. Borsig, A. Fitsche and G. Kristiansen for technical assistance. This work was supported by grants from the Swiss National Science Foundation (M. Y. Donath, D. Konrad), the European Foundation for the Study of Diabetes (EASD/MSD to M. Y. Donath), the Juvenile Diabetes Research Foundation (M. Y. Donath), the Katholieke Universiteit Leuven (GOA 2004/11 and GOA 2008/16, to F.S.), the Gebert Rüf Stiftung (GRS-027/06 to O. Tschopp), the Swiss SystemsX.ch Initiative to the project 'LiverX' of the Competence Center for Systems Physiology and Metabolic Diseases (O. Tschopp and S. M. Schultze) and the University Research Priority Program 'Integrative Human Physiology' at the University of Zürich (J.A. Ehses and M. Y. Donath).

Duality of interest M. Y. Donath is a consultant for Amgen, XOMA, Novartis, Merck, Solianis, and Nycomed. M. Y. Donath is listed as the inventor on a patent (WO6709) filed in 2003 for the use of an IL-1 receptor antagonist for the treatment of or prophylaxis against type 2 diabetes. The patent is owned by the University of Zurich, and M. Y. Donath has no financial interest in the patent. All other co-authors have no duality of interest to report.

\section{References}

1. Donath MY, Schumann DM, Faulenbach M et al (2008) Islet inflammation in type 2 diabetes: from metabolic stress to therapy. Diabetes Care 31(Suppl 2):S161-S164

2. Wellen KE, Hotamisligil GS (2005) Inflammation, stress, and diabetes. J Clin Invest 115:1111-1119

3. Shoelson SE, Goldfine AB (2009) Getting away from glucose: fanning the flames of obesity-induced inflammation. Nat Med 15:373-374

4. Hundal RS, Petersen KF, Mayerson AB et al (2002) Mechanism by which high-dose aspirin improves glucose metabolism in type 2 diabetes. J Clin Invest 109:1321-1326

5. Yuan M, Konstantopoulos N, Lee J et al (2001) Reversal of obesity- and diet-induced insulin resistance with salicylates or targeted disruption of Ikkbeta. Science 293:1673-1677

6. Larsen CM, Faulenbach M, Vaag A et al (2007) Interleukin-1receptor antagonist in type 2 diabetes mellitus. N Engl J Med $356: 1517-1526$

7. Ehses JA, Ellingsgaard H, Boni-Schnetzler M, Donath MY (2009) Pancreatic islet inflammation in type 2 diabetes: from alpha and 
beta cell compensation to dysfunction. Arch Physiol Biochem 115:240-247

8. Chiang SH, Bazuine M, Lumeng CN et al (2009) The protein kinase IKKepsilon regulates energy balance in obese mice. Cell 138:961-975

9. Hong EG, Ko HJ, Cho YR et al (2009) Interleukin-10 prevents diet-induced insulin resistance by attenuating macrophage and cytokine response in skeletal muscle. Diabetes 58:2525-2535

10. Ehses JA, Perren A, Eppler E et al (2007) Increased number of islet-associated macrophages in type 2 diabetes. Diabetes $56: 2356-2370$

11. Ehses JA, Lacraz G, Giroix MH et al (2009) IL-1 antagonism reduces hyperglycemia and tissue inflammation in the type 2 diabetic GK rat. Proc Natl Acad Sci U S A 106:1399814003

12. Patsouris D, Li PP, Thapar D, Chapman J, Olefsky JM, Neels JG (2008) Ablation of CD11c-positive cells normalizes insulin sensitivity in obese insulin resistant animals. Cell Metab 8:301309

13. Medzhitov R (2001) Toll-like receptors and innate immunity. Nat Rev Immunol 1:135-145

14. Takeda K, Akira S (2004) TLR signaling pathways. Semin Immunol 16:3-9

15. Lee JY, Zhao L, Youn HS et al (2004) Saturated fatty acid activates but polyunsaturated fatty acid inhibits Toll-like receptor 2 dimerized with Toll-like receptor 6 or 1 . J Biol Chem 279:16971-16979

16. Lee JY, Sohn KH, Rhee SH, Hwang D (2001) Saturated fatty acids, but not unsaturated fatty acids, induce the expression of cyclooxygenase-2 mediated through Toll-like receptor 4. J Biol Chem 276:16683-16689

17. Shi H, Kokoeva MV, Inouye K, Tzameli I, Yin H, Flier JS (2006) TLR4 links innate immunity and fatty acid-induced insulin resistance. J Clin Invest 116:3015-3025

18. Senn JJ (2006) Toll-like receptor-2 is essential for the development of palmitate-induced insulin resistance in myotubes. J Biol Chem 281:26865-26875

19. Nguyen MT, Favelyukis S, Nguyen AK et al (2007) A subpopulation of macrophages infiltrates hypertrophic adipose tissue and is activated by free fatty acids via Toll-like receptors 2 and 4 and JNK-dependent pathways. J Biol Chem 282:35279-35292

20. Himes RW, Smith CW (2010) Tlr2 is critical for diet-induced metabolic syndrome in a murine model. Faseb J 24:731-739

21. Poggi M, Bastelica D, Gual P et al (2007) C3H/HeJ mice carrying a toll-like receptor 4 mutation are protected against the development of insulin resistance in white adipose tissue in response to a high-fat diet. Diabetologia 50:1267-1276

22. Tsukumo DM, Carvalho-Filho MA, Carvalheira JB et al (2007) Loss-of-function mutation in toll-like receptor 4 prevents dietinduced obesity and insulin resistance. Diabetes 56:1986-1998
23. Ellingsgaard H, Ehses JA, Hammar EB et al (2008) Interleukin-6 regulates pancreatic alpha-cell mass expansion. Proc Natl Acad Sci U S A 105:13163-13168

24. Wueest S, Rapold RA, Schumann DM et al (2010) Deletion of Fas in adipocytes relieves adipose tissue inflammation and hepatic manifestations of obesity in mice. J Clin Invest 120:191-202

25. Wueest S, Rapold RA, Rytka JM, Schoenle EJ, Konrad D (2009) Basal lipolysis, not the degree of insulin resistance, differentiates large from small isolated adipocytes in high-fat fed mice. Diabetologia 52:541-546

26. Boni-Schnetzler M, Boller S, Debray S et al (2009) Free fatty acids induce a proinflammatory response in islets via the abundantly expressed interleukin-1 receptor I. Endocrinology 150:5218-5229

27. Vats D, Mukundan L, Odegaard JI et al (2006) Oxidative metabolism and PGC-1beta attenuate macrophage-mediated inflammation. Cell Metab 4:13-24

28. Suter T, Biollaz G, Gatto D et al (2003) The brain as an immune privileged site: dendritic cells of the central nervous system inhibit T cell activation. Eur J Immunol 33:2998-3006

29. Triantafilou M, Gamper FG, Haston RM et al (2006) Membrane sorting of toll-like receptor (TLR)-2/6 and TLR2/1 heterodimers at the cell surface determines heterotypic associations with CD36 and intracellular targeting. J Biol Chem 281:31002-31011

30. Boni-Schnetzler M, Thorne J, Parnaud G et al (2008) Increased interleukin (IL)-1beta messenger ribonucleic acid expression in beta -cells of individuals with type 2 diabetes and regulation of IL-1beta in human islets by glucose and autostimulation. J Clin Endocrinol Metab 93:4065-4074

31. Cani PD, Amar J, Iglesias MA et al (2007) Metabolic endotoxemia initiates obesity and insulin resistance. Diabetes 56:1761-1772

32. Caricilli AM, Nascimento PH, Pauli JR et al (2008) Inhibition of toll-like receptor 2 expression improves insulin sensitivity and signaling in muscle and white adipose tissue of mice fed a high-fat diet. J Endocrinol 199:399-406

33. Lumeng CN, Bodzin JL, Saltiel AR (2007) Obesity induces a phenotypic switch in adipose tissue macrophage polarization. J Clin Invest 117:175-184

34. Ghanim H, Abuaysheh S, Sia CL et al (2009) Increase in plasma endotoxin concentrations and the expression of toll like receptors and suppressor of cytokine signaling-3 in mononuclear cells following a high fat high carbohydrate meal: implications for insulin resistance. Diabetes Care 32:2281-2287

35. Dasu MR, Devaraj S, Park S, Jialal I (2010) Increased toll-like receptor activation and tr ligands in recently diagnosed type 2 diabetes subjects. Diabetes Care. doi:10.2337/dc09-1799

36. Creely SJ, McTernan PG, Kusminski CM et al (2007) Lipopolysaccharide activates an innate immune system response in human adipose tissue in obesity and type 2 diabetes. Am J Physiol Endocrinol Metab 292:E740-E747 